\title{
COMUNICAÇÃO NAS ORGANIZAÇÕES NO CONTEXTO DA COVID-19
}

\section{COMMUNICATION IN ORGANIZATIONS IN THE COVID-19 CONTEXT}

\author{
VILMAR MICHEREFF JUNIOR \\ Universidade Federal de Santa Catarina - UFSC \\ Mestre em Administração pela Universidade Federal de Santa Catarina - UFSC \\ Orcid: https://orcid.org/0000-0002-9890-351X \\ E-mail: michereff@gmail.com
}

Endereço: Campus Universitário Reitor João David Ferreira Lima, s/no - Trindade

CEP: 88040-900, Florianópolis - SC

\section{SIMONE GHISI FEUERSCHÜTTE}

Universidade do Estado de Santa Catarina - UDESC

Doutora em Engenharia de Produção e Sistemas - UFSC

Orcid: https://orcid.org/ 0000.0002.0963.1242

E-mail: simone.udesc@gmail.com

\section{PATRÍCIA BECKHÄUSER SÁNCHEZ}

Universidade do Estado de Santa Catarina - UDESC

Doutoranda em Administração pela Universidade do Estado de Santa Catarina - UDESC

Orcid: https://orcid.org/0000-0002-4777-2142

E-mail: pbeckhausersanchez@gmail.com

Submissão:15/08/2020. Revisão: 03/10/2020. Aceite: 05/11/2020. Publicação: 29/12/2020. DOI: http://dx.doi.org/10.22277/rgo.v14i1.5752

\section{RESUMO}

A pandemia da COVID-19 trouxe consigo consequências que afetaram as pessoas em diferentes dimensões de seu cotidiano. As alterações de rotina exigiram, além do distanciamento social, a rápida adaptação às novas formas de comunicação a distância. Este estudo se propôs a entender as percepções dos sujeitos da pesquisa acerca da comunicação durante o período de pandemia, tanto no âmbito pessoal quanto no âmbito organizacional ou do trabalho. Para isso, foi realizado um levantamento, a partir da aplicação de questionários online, junto a 120 participantes de organizações públicas, privadas e do terceiro setor. Dentre os resultados, pode-se identificar ampla adesão ao trabalho remoto, bem como aos principais canais de comunicação adotados. A maioria dos participantes relata ter emoções negativas com relação ao uso de tecnologias de comunicação e informação, seja no seu dia a dia, no âmbito pessoal e familiar, ou nas atividades profissionais. Ainda assim, sentem-se seguros e sem maiores dificuldades em utilizá-las no atual momento, ainda que seja necessária a regulamentação quanto ao uso e abordagem de novas formas de comunicação organizacional.

Palavras-chave: Identidade. Comunicação organizacional. Pandemia. COVID-19. 


\begin{abstract}
The COVID-19 pandemic brought with its consequences that affected people in different dimensions of their daily lives. Routine changes required, in addition to social distance, rapid adaptation to new forms of distance communication. This study aimed to understand the research subjects' perceptions about communication during the pandemic period, both in the personal and organizational or work spheres. For this, a survey was carried out, based on the application of online questionnaires, with 120 participants from public, private and third sector organizations. Among the results, broad adherence to remote work can be identified, as well as to the main communication channels adopted. Most participants report having negative emotions regarding the use of communication and information technologies, whether in their daily lives, in the personal and family sphere, or in professional activities. Even so, they feel safe and without major difficulties in using them at the present time, even though it is necessary to regulate the use and approach of new forms of organizational communication.
\end{abstract}

Keywords: Identity. Organizational communication. Pandemic. COVID-19.

\title{
1 INTRODUÇÃO
}

O ano de 2020 ficará marcado como aquele em que a humanidade se viu enfrentando mais uma pandemia em sua história. A COVID-19, doença proveniente de um novo coronavírus, obrigou o mundo a entrar em estado de alerta repentinamente. $\mathrm{O}$ distanciamento social e os novos rearranjos sociais e organizacionais, ainda que temporários, passaram a manifestar também novas formas de os indivíduos enfrentarem suas rotinas.

O distanciamento social tem sido recomendado pelos especialistas por ser, atualmente, a única forma de evitar o contágio. Desta forma, acatando às recomendações da Organização Mundial da Saúde - OMS (BRASIL, 2020), governos das esferas municipal, estadual e federal, órgãos públicos e organizações de modo geral, decretaram o distanciamento físico. Neste contexto, várias pessoas tiveram suas rotinas alteradas, seja no âmbito pessoal, familiar ou organizacional, como a ausência de eventos sociais com aglomerações, o distanciamento social, o trabalho remoto e, consequentemente, a comunicação sendo intensivamente migrada para meios a distância, especialmente os digitais.

Desde meados de março de 2020 , cerca de $50 \%$ da população brasileira encontrava-se em casa o máximo de tempo necessário, mantendo o distanciamento social (INLOCO, 2020). Devido a isso, o consumo de internet no Brasil aumentou entre $40 \%$ e $50 \%$ neste período (LAVADO, 2020). Segundo Deslandes e Coutinho (2020, p. 2480), "o período do isolamento social provocado por esta pandemia coincidiu com o momento de consolidação, popularização e expansão, ainda que desigual para todas as classes sociais, da chamada Internet 2.0".

A Internet 2.0, que experimentamos hoje, possui como principais características a hiperinteratividade entre os usuários e a mobilidade em que podem ser acessados espaços digitais por meio do uso de ferramentas como troca de mensagens de texto, fotos, áudios, transmissão ao vivo, sala de reuniões; em suma, mecanismos que potencializam a interação entre as pessoas (DESLANDES; COUTINHO, 2020). Ainda que metade do Brasil tenha se visto obrigada a se adaptar repentinamente a uma nova maneira de rearranjar a sua rotina pessoal, o acesso facilitado à internet possibilitou a continuidade da comunicação entre as pessoas. Contudo, adaptações também foram necessárias no âmbito organizacional. 
O trabalho remoto, mais especificamente na modalidade home office, foi adotado por $46 \%$ das empresas durante a pandemia (MELLO, 2020). Até junho de 2020, 3 milhões de pessoas ocupadas no setor público e 5,7 milhões de pessoas que atuam no setor privado estavam em regime de trabalho remoto (IPEA, 2020). A despeito de tal quadro ter sido imposto pela pandemia, a modalidade remota de trabalho parece se mostrar como uma tendência, segundo o que mostra uma pesquisa apontando que $74 \%$ das pessoas gostam de trabalhar a partir de casa (TECCHIO, 2020). Outro levantamento indica que $44 \%$ dos entrevistados gostaria de manter o sistema de home office mesmo após o fim da pandemia (TECCHIO, 2020).

Com a distância física então imposta, as organizações tiveram que adaptar seus processos de comunicação interna. Segundo a Associação Brasileira de Comunicação Empresarial (ABERJE, 2020), as mídias sociais (67\%), o portal corporativo (60\%) e os aplicativos para dispositivos móveis (32\%) são os principais canais utilizados pelas áreas ou comitês instituídos nas organizações para tratarem da sua comunicação nesse momento de crise. Segundo o mesmo levantamento, o principal desafio das organizações frente à crise é o de manter os colaboradores engajados e produtivos durante esse período (ABERJE, 2020). Nesse meio tempo, efeitos relacionados à saúde mental e ao bem-estar, como a "sensação de angústia pelo isolamento" e a "ansiedade de desempenho" são citados como barreiras dos indivíduos atuando em regime remoto, que se referem também à administração do tempo (45\%) e às distrações dentro de casa (34\%) como os grandes desafios do home office (TECCHIO, 2020).

O atual contexto de incertezas pode impactar na saúde mental e no bem-estar psicológico devido também às mudanças das rotinas e nas relações familiares (ORNELL et al., 2020). Ornell et al. (2020) alertam que, durante as epidemias, o número de pessoas afetadas em termos de saúde mental tende a ser maior do que o número de pessoas afetadas pela infecção em si.

A partir deste cenário, o objetivo desta pesquisa foi entender as percepções dos indivíduos quanto à comunicação nos contextos pessoal e organizacional durante a pandemia pela COVID-19. Para tanto, buscou-se contextualizar o atual cenário de distanciamento social que, além da consequente adoção abrupta de novos regimes de trabalho a distância - como o home office - e o uso de novas formas de comunicação organizacional, podem provocar efeitos negativos aos indivíduos, como o prejuízo à saúde mental e ao bem-estar psicológico.

Para dar suporte a esta análise foram abordados aspectos da identidade do indivíduo e sua relação com a organização e com a comunicação. A fundamentação teórica reunida neste trabalho, então, busca resgatar definições sobre identidade no contexto das organizações, relacionando-a à comunicação organizacional e considerando o distanciamento social e seus desdobramentos.

A pesquisa tem relevância à medida que busca entender a relação dos sujeitos com as suas formas de comunicação durante a pandemia, ou em outros termos, como se sentem em sua vida pessoal e organizacional quando o assunto é a comunicação. Desta forma, o artigo aborda em sua fundamentação teórica os temas sobre identidade e comunicação organizacional; na sequência são apresentados os procedimentos metodológicos do estudo, os seus resultados e as conclusões. 


\section{IDENTIDADE E COMUNICAÇÃO NAS ORGANIZAÇÕES}

Para que seja possível entender como se dão as questões que envolvem a identidade e a comunicação, tanto no contexto social quanto organizacional, é necessário realizar um resgate bibliográfico que tome os pontos relevantes que norteiem uma discussão do tema. Assim, busca-se compreender os conceitos e definições acerca da identidade e seus desdobramentos, da comunicação no período de surto da COVID-19 e, finalmente, a comunicação e as organizações no contexto da pandemia.

\subsection{IDENTIDADE}

O ser humano é tido como um ser subjetivo, constituído de diversas características, sejam elas inerentes ou adquiridas a partir do meio em que se desenvolve e convive. Como salientam Silva e Henning (2011, p. 67), "o sujeito humano não pode ser entendido como uno ou espécie de entidade total", portanto, não é possível se chegar a uma conclusão única e definitiva do que se trata o ser humano enquanto ser social. O homem não pode ser considerado apenas como um animal racional, uma vez que expressa um complexo de necessidades, desejos, sentimentos, angústias, temores (imaginários ou não), racionalidades e paixões, sendo mais do que um organismo com funções biológicas e psicológicas, possuindo a capacidade de interagir com o meio transformando-o e tornando-se parte do mesmo (AGUIAR, 2015). Ao se partir de uma perspectiva dialética de compreensão do homem e de suas relações sociais, segundo Aguiar (2015), essas interações com diferentes meios aos quais se vincula resultam no processo de construção da identidade do indivíduo.

Conforme Dubar (1996), a identidade pessoal consiste em um processo dinâmico e contínuo, construído pela interação das identidades assumidas e das identidades visadas. Em outras palavras, há um espaço em que se elabora a identidade pessoal, no qual o sujeito entrelaça tanto as características inerentes às suas condutas e pensamentos, quanto as expectativas do que o sujeito pretende ser ou agir. Kraus (2000, p. 3) defende, por exemplo, que o desenvolvimento da identidade se dá como uma colcha de retalhos "criada pelo próprio indivíduo em seus vários mundos da vida". Entretanto, não se trata de uma 'colcha de retalhos acabada', uma vez que a identidade de cada um "pode ser compreendida como constituição do sujeito, desde que seu significado esteja na direção daquilo que se faz aberto e inacabado" (MAHEIRE, 2002, p. 31). Conforme define Machado (2003, p. 54), "construir a própria identidade é, portanto, permanente desafio, no sentido de encontrar o equilíbrio entre aquilo que se é e o que os outros esperam que nós sejamos". Nesse caso, como lembram Markus e Nurius (1986), tanto o passado quanto o futuro influenciam na construção da identidade pessoal; o arcabouço histórico, as prospeç̧ões e as idealizações de um sujeito o constituem como único. Por fim, é possível também compreender que a identidade funciona como um "termômetro" das interações sociais e das influências do outro na vida pessoal (MACHADO, 2003).

Isso porque, como salientam Vignoles, Schwartz e Luyckx (2011, p. 2), a identidade "não compreende apenas 'quem você pensa que é' (individualmente ou coletivamente), mas também 'quem é você quando e como age' nas interações interpessoais e intergrupais" - e o reconhecimento social ou não que essas ações recebem de outros indivíduos ou grupos. Para Hall (2016b, p. 317) a identidade tem também a importância de servir como uma espécie de "ponto fixo do pensamento e do ser, uma base de ação, um ponto parado no mundo em transformação", além de dar sentido à procura do sujeito por um tipo de autenticidade para 
a própria existência. Essa ideia de pertencimento traz consigo a dimensão de uma identidade que extrapola a individualidade.

Considera-se, portanto, a existência da identidade pessoal, relacionada a como o sujeito enxerga a si mesmo e o conjunto de seus padrões comportamentais; da identidade social - referente às relações interpessoais no âmbito familiar, social ou profissional e no trabalho - construída pelos papeis exercidos na socialização no ambiente de trabalho; e da organizacional que constitui, a partir das identidades de seus membros, uma identidade maior atrelada à organização (MACHADO, 2003). Essas diferentes formas de classificação são, além da distinção entre formas de conteúdo de identidade, "diferentes tipos de processos pelos quais as identidades são formadas e mantidas ou alteradas ao longo do tempo" (VIGNOLES; SCHWARTZ; LUYCKX, 2011, p. 3).

Nesse sentido, para além da identidade individual, Machado (2003) destaca a identidade social como mais uma faceta importante na construção da identidade organizacional. Whetten e Godfrey (1998), ao retomarem as ideias de Tajfel (1982), afirmam que a identidade social está atrelada à representação que o sujeito dá a si mesmo quando pertence a um grupo. Uma vez inserido em algum grupo, o indivíduo sente-se total ou parcialmente contemplado por suas opiniões, posições e atitudes, ajudando assim a constituir essa identidade compartilhada, além do fato de que "a definição do outro e de si mesmo é amplamente 'relacional e comparativa'" (ASFORTH; MAEL, 1989, p. 21).

Essas interações e construções sociais da identidade refletem nas relações do indivíduo e do meio organizacional. Conforme análise de Canguilhem (2001), na medida em que os sujeitos de uma organização aprendem o sentido de seu trabalho, passam a se referir a si próprios como pertencentes a este meio (extrapolando a ideia de que estão meramente inseridos), bem como a se submeterem às exigências do referido meio. Em outras palavras, o indivíduo que, de certo modo, consegue influenciar nas próprias normas a seguir, "deixa de se sentir objeto em um meio coercitivo para se perceber sujeito em um meio de organização" (Canguilhem, 2001, p. 116). Ou seja, a interferência direta dos sujeitos em suas próprias condições de trabalho está intimamente ligada ao constructo de sua identidade no trabalho e, ao mesmo tempo, na sustentação da identidade organizacional. Canguilhem (2001, p. 120) conclui, portanto, que os trabalhadores:

não tomariam como autenticamente normais senão as condições de trabalho que eles mesmos teriam instituído em referência a valores próprios e não emprestados, é que o meio de trabalho que eles tomariam como normal seria aquele que eles teriam feito eles mesmos, a eles mesmos, para eles mesmos. Todo homem quer ser sujeito de suas normas.

Partindo do ponto que o trabalho causa impacto na criação e na sustentação das identidades, Machado (2003, p. 52) destaca que "a identidade no trabalho constitui também uma das ramificações da identidade nas organizações". Isto é, a identidade no trabalho é apenas umas das facetas que acabam constituindo a formação de uma identidade organizacional, permeada por várias outras, como a identidade pessoal. Além disso, a "identidade no trabalho também se processa nos planos afetivo e cognitivo" (MACHADO, 2003, p. 59), assim dizendo, em planos no qual a subjetividade se manifesta com intensidade.

Uma vez que o ser humano é um ser subjetivo, que constrói e é construído pelos meios nos quais coabita, incluindo o âmbito organizacional, aponta-se a comunicação como o caminho de troca para essas construções. Segundo Pavlov (1963) e, analogamente, Chanlat (1996), nossas formas mais aprimoradas de comunicação somente são possíveis graças à característica humana do aprendizado, que abre caminhos para a criação de um segundo 
sistema de sinalização, diferentemente dos demais animais: a linguagem e o pensamento consciente.

Por meio do aprendizado várias transformações sociais foram possíveis, como o surgimento da ciência e da comunicação. Ao terem a capacidade de criar palavras e de compreendê-las, os humanos passam a transmitir mensagens mais complexas. Entretanto, nas formas de comunicação humanas mais complexas moram também as suas subjetividades. Diferentemente de uma simples transmissão de informação, a comunicação pelo discurso carrega diferentes tons sobre o agir, o fazer, o pensar e o sentir (CHANLAT, 1996). Isto é, a comunicação carrega consigo traços da identidade do indivíduo que, por sua vez, possui critérios objetivos e subjetivos.

Hall (2016a, p. 18) sustenta que a “linguagem é um dos 'meios' através do qual pensamentos, ideias e sentimentos são representados numa cultura", considerando a cultura como um espaço de criação e troca de significados dentro de um grupo ou sociedade, "além de estar relacionada a sentimentos, conceitos, ideias e o senso de pertencimento". Isto significa que, para Hall (2016a, p. 42), "o sentido é construído pelo sistema de representação", que possui ligação direta com os meios aos quais o indivíduo pertence, sendo também permeado pela cultura que sustentou a criação desse sistema de representação e a definição de códigos que formam essa linguagem.

As diferentes nuances nas comunicações, consequência dos meios, das culturas e das identidades que as constituíram, podem causar diferentes compreensões, também influenciadas pela subjetividade de quem as recebe e as processa.

\subsection{A COMUNICAÇÃO DURANTE A PANDEMIA}

O distanciamento social adotado como um dos meios contra o contágio pelo novo coronavírus impactou a vida das pessoas e, em particular, considerando a forçada interrupção nas interações do cotidiano social, pode ter afetado a configuração da identidade social dos indivíduos.

Devido às características ou natureza de algumas atividades laborais, o distanciamento não pôde ser adotado, como é o caso dos profissionais da área da saúde - os profissionais da "linha de frente" - e de outros serviços essenciais, como mercados, farmácias, segurança e vigilância, fiscalização, entre outros (BRASIL, 2020). Entretanto, em atividades passíveis de adequação à modalidade a distância, o distanciamento social mostrou-se viável e recomendado aos profissionais, que buscaram se adaptar ao trabalho remoto, como o home office.

Além da adoção do trabalho remoto para os casos em que foi possível, destacam Deslandes e Coutinho (2020, p. 2481), "[...] que a rotina das pessoas passou a ser mediada exclusivamente pelo mundo digital, tentando imprimir uma agenda de atividades capazes de ocupar de 'forma saudável' o tempo de isolamento". Exercícios físicos acompanhados por vídeo, podcasts, lives, reuniões, festas, cursos e apresentações online, jogos de azar e disputa de videogames em rede são apenas alguns exemplos desta mediação digital. A expectativa é que a circulação e a interação nos ambientes digitais, no contexto da pandemia, possam evitar os diversos efeitos colaterais que o distanciamento social tende a ocasionar. É o caso da depressão, da ansiedade, da solidão, do estresse (WANG et al., 2020), ou mesmo situações mais graves, como "a maior vulnerabilidade às violências familiares e entre parceiros, possíveis tentativas de suicídios ligados à falta da sociabilidade presencial e ao clima social de 
Vilmar Michereff Junior, Simone Ghisi Feuerschütte e Patrícia Beckhäuser Sánchez

medo em relação aos desdobramentos da pandemia" (DESLANDES; COUTINHO, 2020, p. 2481).

Esses reflexos foram abordados em um estudo realizado na China, citado por Vasconcelos et al. (2020). O resultado aponta que 53,8\% dos entrevistados avaliaram o impacto psicológico da epidemia como moderado ou grave; $16,5 \%$ relataram sintomas depressivos moderados a graves, enquanto $28,8 \%$ dos participantes relataram sintomas de ansiedade moderados a graves e $8,1 \%$ relataram níveis de estresse moderado a grave. Além disso, a maioria dos entrevistados relatou ficar de 20 a 24 horas por dia em casa.

Para evitar parte destes problemas, a OMS (2020) recomendou que, neste momento, as pessoas passem a manter rotinas e tarefas regulares sempre que possível, criando atividades em ambientes diferentes da residência, como atividades diárias, limpeza, canto, pintura dentre outras. A OMS também destacou que o apoio social e o contato regular com pessoas mais próximas e entes queridos é um fator de proteção que ajuda os indivíduos a lidarem com situações estressantes de forma mais eficaz e ressaltando que, para isso, sejam utilizados mecanismos não presenciais para entrar em contato com o outro e fortalecer o apoio social, como ligações telefônicas e chamadas de vídeo, e-mails e redes sociais (OMS, 2020; VASCONCELOS et al., 2020). As mudanças na comunicação durante a pandemia extrapolam o âmbito pessoal do sujeito, uma vez que as organizações também tiveram que se adaptar ao novo contexto.

\subsection{A COMUNICAÇÃO E AS ORGANIZAÇÕES NO CONTEXTO DA PANDEMIA}

Uma das questões que permeiam a comunicação organizacional, particularmente no contexto da pandemia, foco deste artigo, pode ser reconfigurada de um questionamento de Putman, Phillips e Chapman (2004), ao estudarem a relação entre comunicação e organização. Os autores levantaram a seguinte questão: "É a organização que determina o tipo e o fluxo de comunicação ou é a comunicação que se molda à natureza da organização?". Em meio às novas rotinas da sociedade, resultantes das condições impostas pela pandemia, a questão de Putman, Phillips e Chapman (2004) poderia aqui ser assim parafraseada: É o distanciamento social que determina o tipo e o fluxo de comunicação ou é a comunicação que se molda à natureza do distanciamento social?

Cabe refletir, então, na antemão dos resultados, se as formas de comunicação organizacional a distância, adotadas durante a pandemia, já podem demonstrar tendências em relação à dimensão de seu uso ou se as organizações ainda levarão um tempo para adaptar-se melhor à nova realidade.

Como já mencionado, a identidade humana é subjetiva (MAHEIRE, 2002; AGUIAR, 2015), constrói-se a partir das relações do sujeito com o meio em que vive e influencia na construção dos ambientes em que se insere (CANGUILHEM, 2001; MACHADO, 2003; VIGNOLES; SCHWARTZ; LUYCKX, 2011), sendo permeada pela comunicação, que pode ser transmitida e captada diferentemente de acordo com a percepção de cada sujeito (CHANLAT, 1996; HALL, 2016a). Nessa perspectiva, pode-se questionar, então, no cerne deste trabalho: como a comunicação é percebida pelos indivíduos no contexto da pandemia, seja em termos pessoais quanto no âmbito organizacional? Para refletir sobre este questionamento, parece interessante indicar pontos que auxiliem na compreensão sobre a comunicação organizacional e ao que ela implica no cenário atual da pandemia.

Para Deetz (2010) a comunicação é uma ferramenta muito importante para as atividades organizacionais, essencial para que elas se mantenham ativas e produtivas. Curvello (2009), por sua vez, esclarece que a comunicação organizacional só é eficaz quando 
a informação é estrategicamente facilitada para todos, levando em consideração o respeito à pluralidade dos indivíduos e a participação mútua. Em outras palavras, a comunicação organizacional não deve ser direcionada apenas a publicações com o objetivo único de transmitir uma mensagem (DEETZ, 2010). Neiva (2018) sustenta que devem ser construídos novos moldes à comunicação organizacional, que estimulem a interação entre diferentes setores e escalões da organização, ampliando o diálogo, estreitando as relações, encontrando consensos e transpondo obstáculos para as mais variadas situações nos ambientes organizacionais.

Chanlat e Bédard (1996) já haviam destacado obstáculos ao diálogo no ambiente de trabalho, como "a ideologia e os valores que a ela veicula; a 'língua' administrativa em si mesma, os jargões especializados; e a estrutura burocrática" (CHANLAT; BÉDARD, 1996, p. 140). Tais obstáculos, ao refletirem os pensamentos dominantes na gestão das organizações, refletem-se também na comunicação, por vezes afetando a maneira como as mensagens são recebidas e que reações delas emergem. Como destaca Hatch (2013, p. 14), "o poder das palavras é transferido para aqueles que têm melhor acesso ou influência no discurso dominante". Ou seja, quem detém o poder, ao comunicar-se com base em seus valores ideológicos, pode acabar criando distorções e barreiras comunicativas, definindo a realidade em que outros devem viver e criando potencial para exploração e abuso (HATCH, 2013). A ideologia gerencial, por exemplo, é um desses pensamentos que permeiam o ambiente organizacional, como exemplificam Chanlat e Bédard (1996), e que pode dificultar a fluidez da comunicação.

A linguagem ou o idioma administrativo é outro obstáculo direto à comunicação, às formas com que a organização se apresenta, se facilita ou dificulta a transmissão e compreensão. Ela pode estar formalizada no dia a dia, ou então recheada de jargões administrativos que podem tornar a comunicação fria, vazia, excessivamente direta e padronizada. A mensagem, seja ela escrita, falada, desenhada ou expressa, carrega traços da forma como é manifestada, os quais impactam diretamente na decodificação (HALL, 2016a). Junta-se à essa lógica o uso excessivo de jargões especializados, que distanciam a compreensão de quem está acostumado a expressões mais coloquiais (CHANLAT; BÉDARD, 1996).

A estrutura burocrática também é citada por Chanlat e Bédard (1996) como um obstáculo na comunicação organizacional. A multiplicação nos níveis hierárquicos gera a fragmentação de toda a estrutura, criando mais divisões de responsabilidades e tarefas e, consequentemente, conflitos de interesses. Estes ruídos, muitas vezes, acabam resultando em uma comunicação organizacional fracionada, em outros termos, que pode perder significados e sentidos na medida em que se propaga. Essa fragmentação também reflete em diferentes aspectos da identidade organizacional (ASFORTH; MAEL, 1989).

Um destes aspectos é a identidade holográfica, ou melhor, aquela que "seria a da alta administração, e ela percorreria toda a organização, podendo ser evidenciada em qualquer parte desta" (CARRIERI; PAULA; DAVEL, 2008, p. 132), e a ideográfica, "quando não há uma unidade sobre a identidade da organização; consequentemente diferentes grupos, subgrupos e unidades da organização mantêm múltiplas identidades" (MACHADO, 2003, p. 62). Como a identidade no trabalho consiste na interação profissional que ocorre em uma organização entre seus indivíduos (MACHADO, 2003), boa parte destas interações ocorre pela comunicação.

Entretanto, Chanlat e Bédard (1996) trazem também algumas condições favoráveis ao diálogo no ambiente de trabalho: os valores, a dinâmica dos grupos informais e as práticas 
adotadas por líderes de grupo. De acordo com estes autores, um traço ocidental tido como valor marcante é "a emancipação da pessoa, cujos direitos de expressão têm sido, ao longo tempo, sempre reforçados" (CHANLAT; BÉDARD, 1996, p. 144). Além disso, as pessoas inseridas em uma organização podem também compartilhar valores (ASFORTH; MAEL, 1989).

A maneira com que alguns grupos informais trocam informações, profissionais ou não, de interesse pessoal ou coletivo, de forma mais sinérgica do que com o grupo em geral é tida como uma manifestação positiva e que pode auxiliar na compreensão de como a comunicação pode ser aprimorada num contexto organizacional (CHANLAT; BÉDARD, 1996). Ao passo em que "as transformações tecnológicas têm promovido outros hábitos e experiências comunicacionais, tanto em âmbito individual quanto organizacional", é possível dizer que experimentamos hoje, em ambos os contextos, "a comunicação por meio de novos suportes, lógicas, apropriações e linguagens" (SCHEID; MACHADO; PÉRSIGO, 2019, p. 16), que facilitam a troca mais sinérgica de informações defendida positivamente por Chanlat e Bédard (1996).

Por fim, a forma com que as organizações se preocupam com práticas mais humanizadas (CHANLAT; BÉDARD, 1996; ABERJE, 2020) se reflete também na comunicação, quando deixam mais livres as manifestações, aceitam a liberação da fala, da palavra, da conversa, demonstra reflexos positivos, especialmente quando institucionalizam as práticas e comportamentos espontâneos de qualquer grupo informal. A adoção de uma comunicação mais humanizada, como já apontavam Chanlat e Bédard (1996) como um aspecto que se mostra benéfico nas organizações, tem sido, inclusive, encarada como uma das grandes mudanças decorrentes da crise da COVID-19 (ABERJE, 2020).

Tendo em vista que o ser humano é um indivíduo que se comunica, cabe um melhor entendimento de como tem sido a compreensão de sujeitos inseridos nas dinâmicas comunicacionais que se estabeleceram com o início da pandemia do COVID-19. Foi com este intuito que se buscou aplicar a presente pesquisa, cujos procedimentos metodológicos são descritos a seguir.

\section{METODOLOGIA}

A presente pesquisa, implementada sob um design quantitativo (CRESWELL, 2009), constituiu-se como um estudo de levantamento (tipo survey) que abordou a descrição de percepções dos sujeitos sobre o fenômeno de interesse, segundo uma lógica indutiva e aplicação de técnica estatística de distribuição de frequências. Adicionalmente, também foram utilizados procedimentos complementares de natureza qualitativa, com a aplicação de perguntas abertas aos sujeitos que constituíram o grupo pesquisado.

A lógica indutiva se justifica por abordar uma problemática - a questão da comunicação organizacional no contexto da pandemia da COVID-19 - e o seu entendimento por diferentes indivíduos, em termos de suas percepções ao longo da experiência consequente ao fenômeno. A indução pode ser considerada como "um processo mental por intermédio do qual, partindo de dados particulares, suficientemente constatados, infere-se uma verdade geral ou universal, não contida nas partes examinadas" (MARCONI; LAKATOS, 2010, p. 86).

Assim, com vistas a compreender aspectos da comunicação durante a pandemia da COVID-19, considerando aspectos da identidade dos sujeitos e seus reflexos na vida social e organizacional, buscou-se neste estudo exploratório analisar características específicas do grupo abordado, bem como processos vivenciados em termos de suas interações sociais, particularmente relacionadas à comunicação. Para tanto, foi aplicado um questionário com 33 perguntas, distribuídas nas seguintes categorias: (1) Perfil socioeconômico (8 questões 
fechadas); (2) Comunicação no contexto pessoal (10 questões, sendo 8 fechadas e 2 abertas) e; (3) Comunicação no contexto organizacional (15 questões, sendo 13 fechadas e 2 abertas).

O questionário foi enviado, aleatoriamente, para cerca de 300 pessoas, sob o critério de acessibilidade - listagem de contatos pré-definida -, as quais formaram a população do estudo. O caráter exploratório da pesquisa teve como foco estudar a comunicação de um modo mais amplo, particularmente associada ao cenário da pandemia que está impactando a todos os grupos de indivíduos. Os participantes foram convidados a participar por mensagens diretas enviadas via e-mail e Facebook ${ }^{\circledR}$. Foram chamados a participar indivíduos inseridos em diferentes tipos de organização (públicas, privadas e do terceiro setor), bem como oriundos de diferentes cidades, configurações familiares, entre outros. Organizado na plataforma digital Google Forms ${ }^{\circledR}$, o instrumento de coleta de dados foi aplicado entre os dias 30 de julho e 4 de agosto de 2020, tendo-se obtido 128 retornos. No momento da avaliação dos resultados da pesquisa foi constatado que 8 dos respondentes não possuíam vínculos organizacionais, portanto, suas respostas foram desconsideradas, uma vez que o vínculo organizacional era condição necessária para os propósitos do estudo. Os dados foram trabalhados por meio de técnicas de estatística descritiva e analisados a partir da definição e caracterização das categorias já explicitadas.

\section{ANÁLISE E DISCUSSÃO DOS RESULTADOS}

As informações obtidas com o levantamento realizado foram organizadas em três categorias trabalhadas no estudo: perfil socioeconômico, contexto pessoal e contexto organizacional. Essas categorias estão alinhadas ao referencial teórico, uma vez que é possível observar características da comunicação e seus efeitos nos sujeitos em ambos os contextos estudados nesta pesquisa, levando em conta o aspecto da identidade, além de também atenderem ao objetivo proposto pela pesquisa, de verificar a percepção dos indivíduos sobre questões da comunicação no contexto pessoal e organizacional durante a pandemia pelo COVID-19.

\subsection{PERFIL SOCIOECONÔMICO}

O perfil socioeconômico é uma das três categorias trabalhadas neste estudo, composta pelas seguintes variáveis: gênero, idade, estado civil, identificação étnico-racial, com quem reside, região onde vive, formação educacional e organização a qual pertence.

A partir da análise, é possível descrever o perfil socioeconômico geral dos 120 participantes. Quanto ao gênero, 50,5\%, afirmam ser homens e 49,5\% mulheres. Entre os respondentes, $77 \%$ possuem idade entre 26 e 40 anos, sendo $7,7 \%$ composto de pessoas entre 51 e 70 anos. $78 \%$ são brancos, $68,1 \%$ são solteiros, $75,5 \%$ moram com os pais, cônjuges e filhos, $79 \%$ vivem no Sul e Sudeste e 95,6\% possuem formação acima do ensino médio. Também foi possível identificar as formas de vínculo organizacional dos respondentes, verificando-se equilíbrio entre indivíduos que atuam em instituições públicas e privadas (Gráfico 1). 
Gráfico 1 - Atuação profissional dos participantes da pesquisa

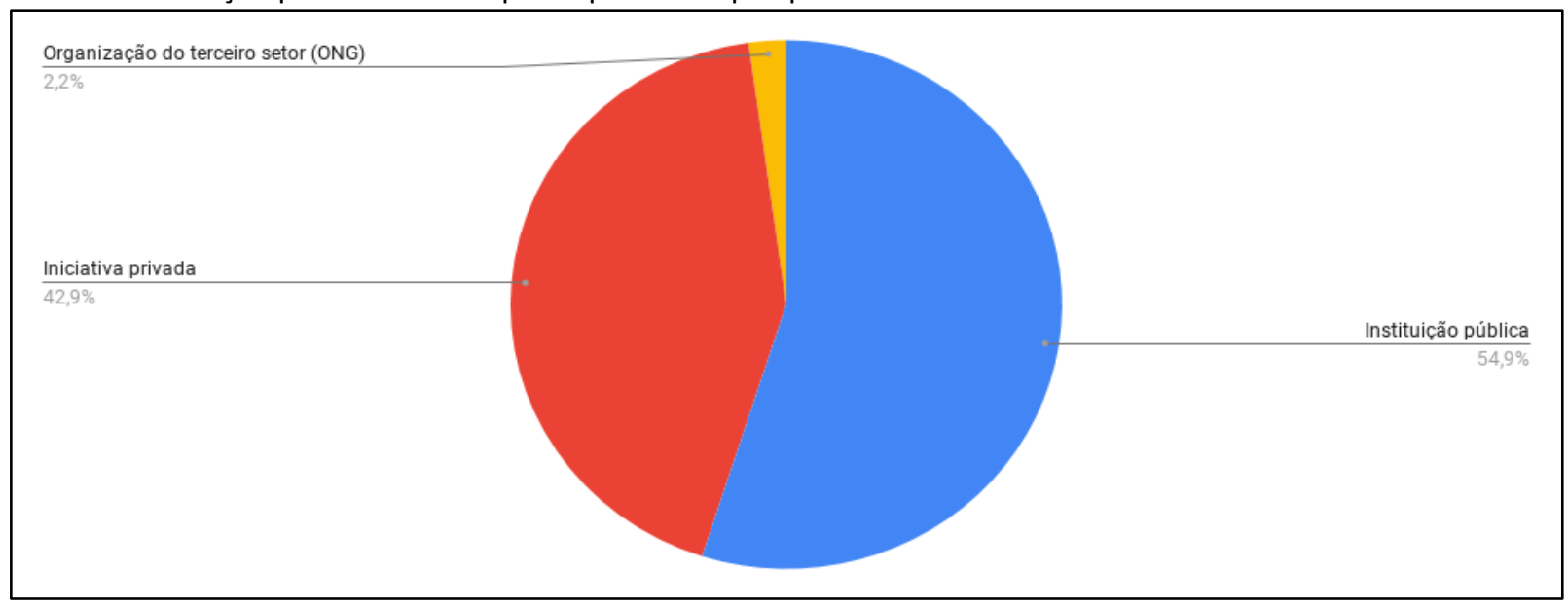

Fonte: elaborado pelos autores, com base nos dados da pesquisa (2020).

Conhecendo o perfil socioeconômico, passa-se a analisar melhor os contextos em que os respondentes estão inseridos.

\subsection{CONTEXTO PESSOAL}

A segunda categoria deste estudo diz respeito à relação da comunicação no contexto pessoal, ou seja, no dia a dia do sujeito pesquisado. Nesta seção, considerou-se o ambiente social dos indivíduos e seus meios de comunicação acionados durante o período da pandemia, como as mídias, aplicativos e plataformas digitais. Além disso, buscou-se coletar aspectos da percepção destes indivíduos ao utilizarem estes meios de comunicação em meio ao distanciamento social.

A primeira questão aborda quais meios de comunicação o entrevistado tem utilizado com mais frequência para manter o contato com os grupos sociais e familiares. Foram listados alguns meios de comunicação, hipoteticamente mais utilizados, o que permitiu aos participantes assinalarem mais de uma ou até todas as opções (Gráfico 2).

Gráfico 2 - Meios de comunicação utilizados com mais frequência pelos respondentes em seu contexto social

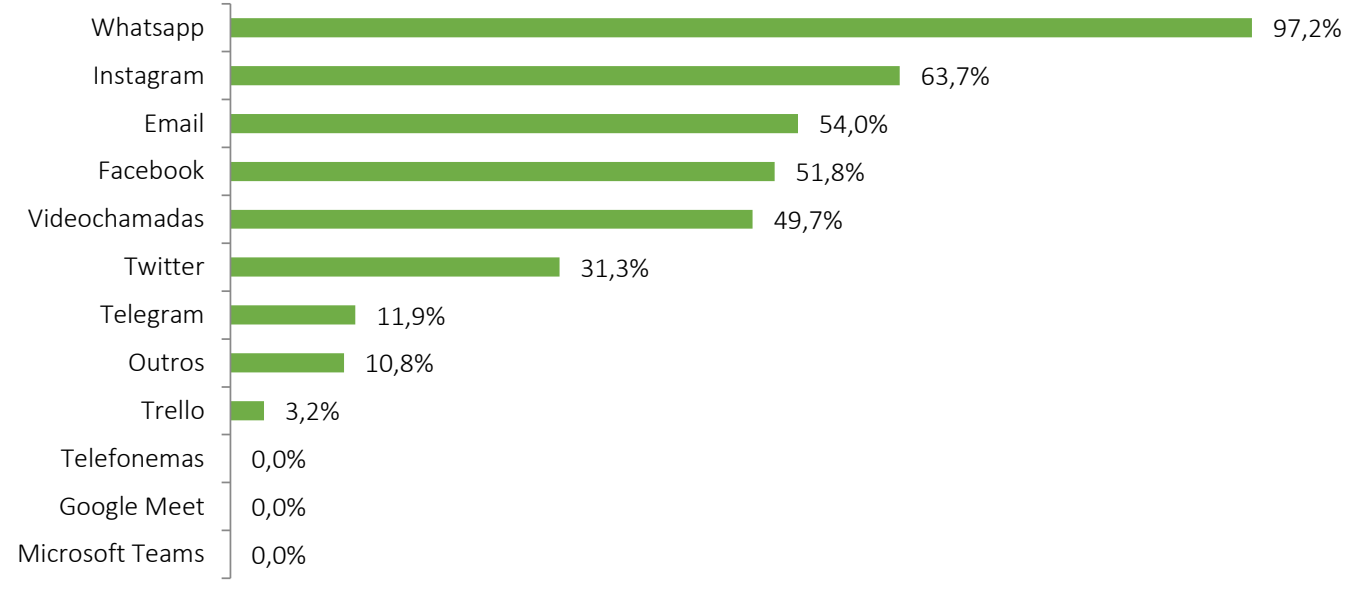

Fonte: elaborado pelos autores, com base nos dados da pesquisa (2020).

Os meios de comunicação mais citados foram WhatsApp ${ }^{\oplus}$, Instagram ${ }^{\circledR}$, correspondências eletrônicas (e-mails), Facebook ${ }^{\circledast}$ e videochamadas em geral. As indicações podem ser explicadas pela popularidade destes aplicativos, redes sociais e meios de 
comunicação antes mesmo da pandemia, bem como a gratuidade de seus acessos. Já as videochamadas em geral, citadas também em outros momentos da pesquisa, confirmam os dados de um levantamento que aponta o aumento de até $65 \%$ do uso de plataformas de chamadas de vídeo durante a pandemia (MOURA, 2020).

A segunda questão busca entender que forma de comunicação era a mais utilizada, no que $82,4 \%$ mencionaram a escrita como a mais adotada por eles neste período de pandemia, o que pode explicar os quatro primeiros colocados do Gráfico 2.

Quanto à frequência de comunicação, aplica-se a seguinte questão: "Em uma escala de 1 a 5, qual tem sido a sua frequência de comunicação com seus grupos familiares e sociais? Considere 3 como 'permanece igual a antes do distanciamento social', 1 para 'diminuiu drasticamente' e 5 para 'aumentou drasticamente'". As respostas foram coletadas em escala Likert, um tipo de escala de resposta psicométrica que permite avaliar o nível de concordância do participante com a opinião expressa na questão ou a frequência informada quanto a determinado comportamento (COSTA; ORSINI; CARNEIRO, 2018). Perguntados sobre a frequência de comunicação com seus grupos familiares e sociais, $75,6 \%$ dos respondentes afirmaram que manteve ou aumentou a frequência após o início do distanciamento social.

A fim de buscar elementos acerca da identidade neste contexto, elaborou-se questões, fechadas e abertas. Inicialmente, solicitava-se que os respondentes descrevessem suas emoções quando utilizam os meios de comunicação a distância durante a pandemia. Foram listadas algumas emoções, adaptadas de Richins (1997), em uma relação equilibrada, sendo possível ao respondente assinalar mais de uma ou até todas as opções (Gráfico 3).

Gráfico 3 - Emoções mais citadas pelos respondentes quando utilizam meios de comunicação a distância em seu contexto social

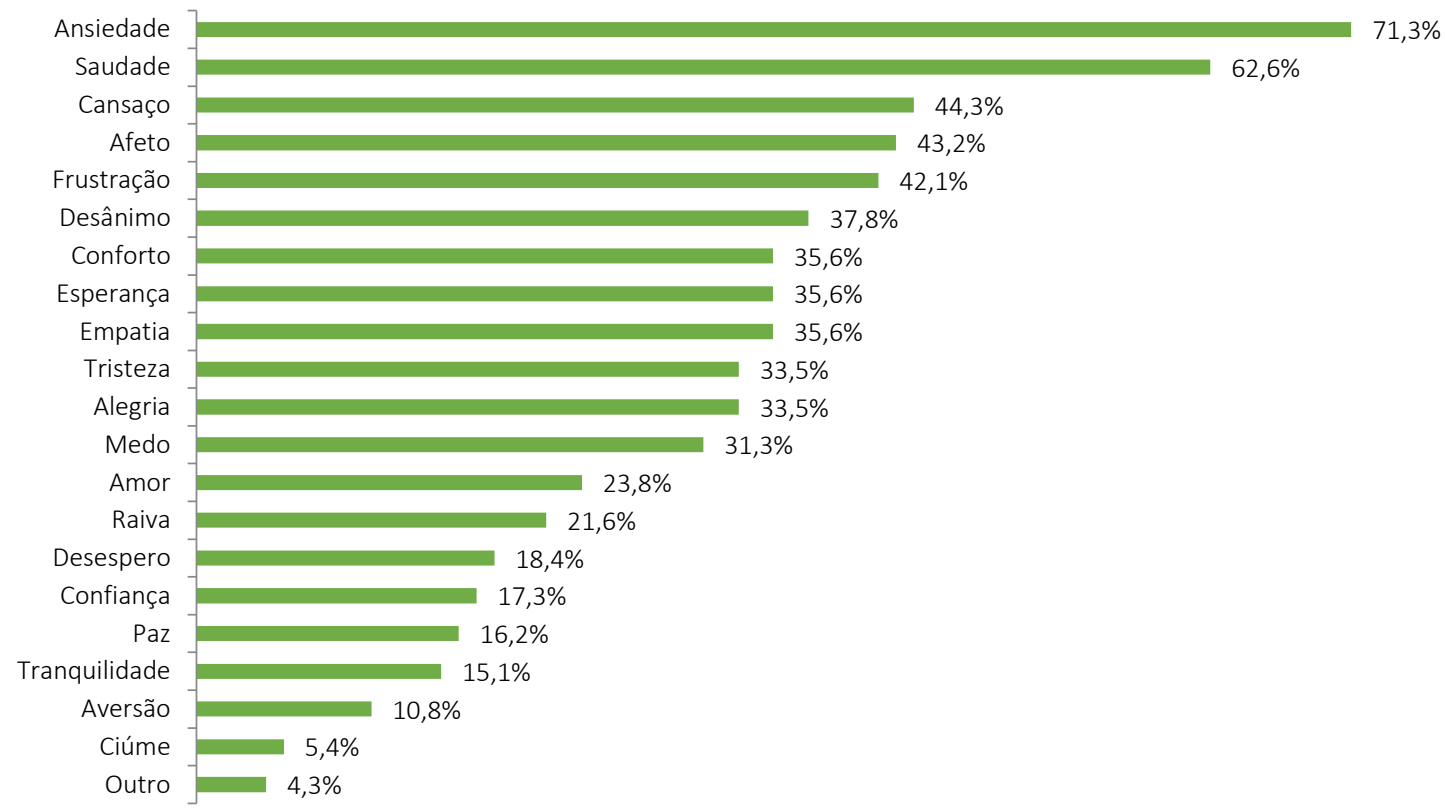

Fonte: elaborado pelos autores, com base nos dados da pesquisa (2020).

A ansiedade foi citada por $71,3 \%$ dos participantes, seguida de saudade $(62,6 \%)$, cansaço $(44,3 \%)$, afeto $(43,2 \%)$, frustração $(42,1 \%)$ e desânimo $(37,8 \%)$. Nota-se que o processo de comunicação a distância pode despertar diferentes emoções, em maior ou menor intensidade, as quais podem ser associadas à diversidade das identidades individuais e seus mecanismos de expressão (MAHEIRIE, 2002; HALLb, 2016). Quando perguntados sobre quais têm sido os efeitos emocionais que as mídias sociais e outras tecnologias (internet, canais de 
TV, podcasts, rádio) têm gerado durante a pandemia, $46,2 \%$ participantes do estudo afirmaram que elas interferem negativamente no seu humor, enquanto $31,8 \%$ disseram que interferem positivamente e $22 \%$ que não interferem.

Como destacam Wang et al. (2020), sintomas de depressão, ansiedade e estresse diante da pandemia têm sido identificados na população geral. Além disso, os efeitos negativos do distanciamento social incluem manifestações como estresse pós-traumático, confusão e raiva, bem como as preocupações com a escassez de suprimentos e as perdas financeiras, que também acarretam prejuízos ao bem-estar psicológico, uma vez que pode desencadear sintomas associados à ansiedade e à depressão (BROOKS et al., 2020; SCHMIDT et al., 2020). Tais aspectos podem ser acrescidos pelo próprio "[...] medo de ser infectado por um vírus potencialmente fatal, de rápida disseminação, cujas origens, natureza e curso ainda são pouco conhecidos", o que acaba por "afetar o bem-estar psicológico de muitas pessoas" (Schmidt et al., 2020, p. 3).

Outro aspecto explorado no levantamento, buscando respostas mais amplas da dimensão da identidade, foi sobre como a comunicação tem interferido no cotidiano do participante e na forma como vem se relacionando com seus grupos familiares e sociais. Acerca dessa questão, a falta do contato pessoal foi um dos pontos mais mencionados pelos respondentes, como expressam as seguintes frases: "Sinto falta do contato pessoal, isso tem afetado meu estado emocional, gerando diferentes níveis de ansiedade"; "[...] de forma vaga, pouca emoção, pouca linguagem corporal"; "[...] perda de contato mais profundo com as pessoas [...]" e "a falta do contato presencial levou ao distanciamento em relação a certos grupos sociais, principalmente familiares". Estes relatos são mencionados devido ao argumento de que, por exemplo, "a distância física provoca uma distância geral também, não tenho falado com pessoas que em tempos normais eu veria e falaria todos os dias".

Por outro lado, notou-se que muitos responderam que se aproximaram mais de algumas pessoas durante este período: "Interferiu positivamente em algumas relações" e "[...] tenho me aproximado um pouco mais de quem mora longe de mim". Foram apontados, ainda, efeitos sobre a aproximação devido ao uso da própria tecnologia, como referido na resposta "[...] tem aumentado, considerando a impossibilidade das pessoas se encontrarem", incluindo uma maior frequência de comunicação "especialmente com a família, em que começaram as videochamadas".

A comunicação, em si, como relatado pelos informantes, se mostra bem importante neste momento de distanciamento social. Foram obtidas, neste sentido, respostas como: "Tem sido de extrema importância, pois não posso estar próximo deles"; "[...] a comunicação tem sido uma aliada muito importante pra mim"; "[...] tem sido essencial"; "ultimamente têm sido muito maior do que antes". Foi citado, entretanto, que há diferença na comunicação virtual: "Há uma interação diferente. Não há plena transmissão de sentimentos, olhares, emoções como em uma conversa em pessoa".

Em síntese, as 92 respostas recebidas à questão aberta mencionada acima - Como a comunicação tem interferido no seu cotidiano e na forma como vem se relacionando com seus grupos familiares e sociais? - foram analisadas e catalogadas em quatro categorias: interferência positiva (quando houve apenas citações positivas); interferência mista (quando houve citações positivas e negativas); interferência negativa (quando houve apenas citações negativas) e; indefinido/indeterminado (cuja resposta não pode ser classificada). $41,3 \%$ dos respondentes apresentaram interferências exclusivamente positivas, enquanto $23,9 \%$ apresentaram argumentações tanto positivas quanto negativas; algumas argumentações 
foram exclusivamente negativas $(17,4 \%)$ e em algumas respostas a interferência não foi citada ou não pôde ser definida $(17,4 \%)$.

A segunda questão aberta aos respondentes no contexto pessoal solicitava que fossem citados novos comportamentos de comunicação adotados durante o distanciamento social que pretendem estender para depois do fim da pandemia. Das 82 respostas obtidas (questão não obrigatória), pode-se destacar algumas respostas em comum: 42 citaram a realização de videochamadas, enquanto outras 20 disseram que pretendem utilizar mais os meios virtuais de comunicação; essa tendência também foi verificada na relação dos participantes da pesquisa com suas organizações, tal como apresentam os dados a seguir.

\subsection{CONTEXTO ORGANIZACIONAL}

Mais especificamente, sobre o contexto organizacional onde os sujeitos da pesquisa estão vinculados, foi perguntado acerca da modalidade de trabalho adotada neste período. As respostas foram:

a) Instituições públicas: $82,2 \%$ está em regime de trabalho remoto; 15,6\% em regime semipresencial; $2,2 \%$ em regime presencial;

b) Iniciativa privada: $60,5 \%$ está em regime de trabalho remoto; $10,6 \%$ em regime semipresencial; 28,9\% em regime presencial;

c) Organizações do terceiro setor: $100 \%$ está em regime semipresencial.

É possível considerar, a partir desses dados, um número consideravelmente alto de pessoas trabalhando em regime remoto ou semipresencial, com maior adesão das instituições públicas.

Quanto aos tipos de comunicação adotados ou intensificados pela organização após o início da pandemia, foram indicadas várias opções para escolha dos respondentes (de uma até todas as opções poderiam ser assinaladas) (Gráfico 4).

Gráfico 4 - Meios de comunicação mais adotados pelas organizações

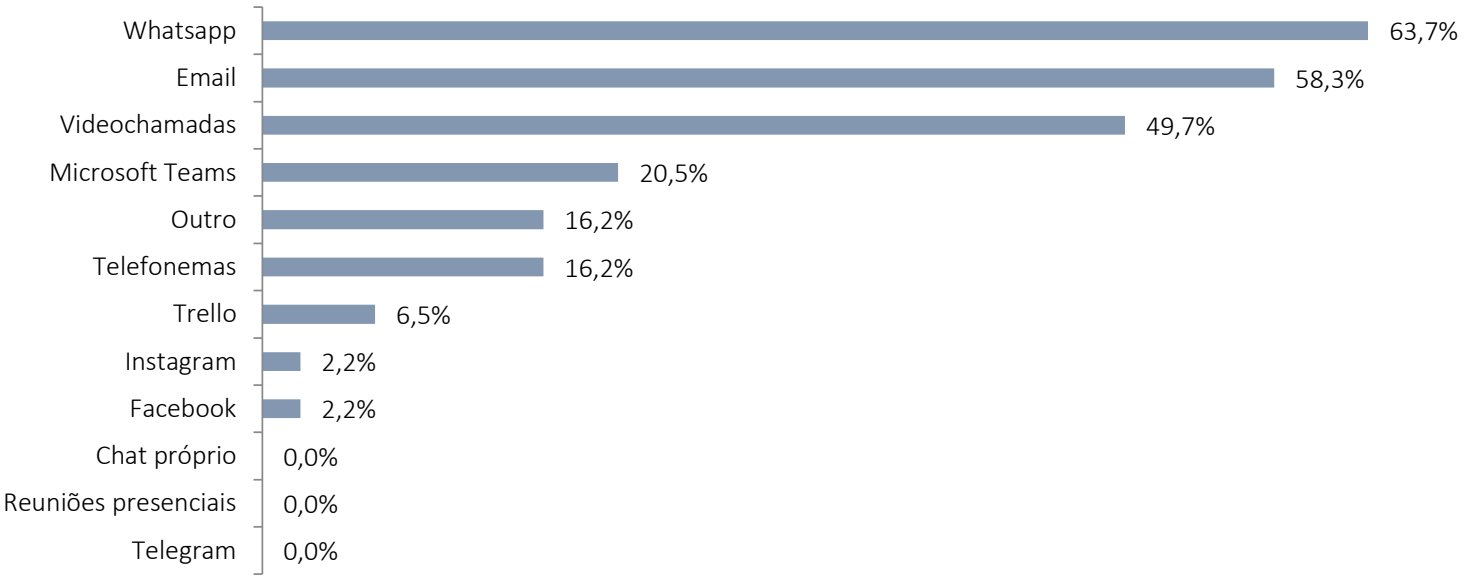

Fonte: elaborado pelos autores, com base nos dados da pesquisa (2020).

Assim como no contexto pessoal, o WhatsApp ${ }^{\varpi}$ foi o recurso de comunicação mais citado $(63,7 \%)$, seguido pelos também citados anteriormente e-mail $(58,3 \%)$ e videochamadas em geral $(49,7 \%)$. Outros tipos também foram citados, mas em menor intensidade. É possível observar que alguns apontamentos realizados são semelhantes ao contexto pessoal, ao passo em que aplicativos habitualmente mais utilizados para a comunicação pessoal e não formal, como o Facebook ${ }^{\oplus}$ e o Instagram ${ }^{\circledR}$, ainda figuram, porém de forma mais tímida (2,2\% cada). 
Ao mesmo tempo, ferramentas mais conhecidas por seu uso profissional, como o Microsoft Teams ${ }^{\oplus}$ e o Trello $^{\oplus}$, aparecem entre as citadas.

Já os telefonemas, que surgem aqui em quinto lugar, não foram mencionados no contexto pessoal, o que pode ser explicado devido ao caráter de urgência e por ser a forma mais tradicional com que determinados assuntos profissionais demandam ao serem tratados em um regime de trabalho a distância. A ausência de reuniões presenciais, como um dos principais meios de comunicação durante a pandemia, reforça a ideia de que as organizações têm buscado atender as recomendações de distanciamento social.

Os respondentes não apresentam uma tendência quando o assunto é a frequência de comunicação organizacional: de modo similar se comunica menos, se comunica como antes ou se comunica mais, mostrando um resultado equilibrado. De modo geral, 34,2\% dizem ter se comunicado menos do que antes do início do distanciamento social, enquanto $32,9 \%$ indicam ter se comunicado na mesma frequência e 32,9\% se comunicado mais. Já a frequência de comunicação com os colegas de organização demonstrou certa tendência. Seja sobre assuntos profissionais ou corriqueiros, $45,9 \%$ dizem estar se comunicando menos durante a pandemia.

Do mesmo modo que se investigou em relação ao contexto social, uma das questões do contexto organizacional solicitava que fossem destacadas as emoções sentidas/percebidas quando utilizados os meios de comunicação a distância, durante a pandemia. Foram listadas emoções (RICHINS, 1997) em uma relação equilibrada, sendo possível assinalar mais de uma ou até todas as opções (Gráfico 5).

Gráfico 5 - Emoções mais citadas pelos respondentes quando utilizam meios de comunicação a distância em seu contexto organizacional

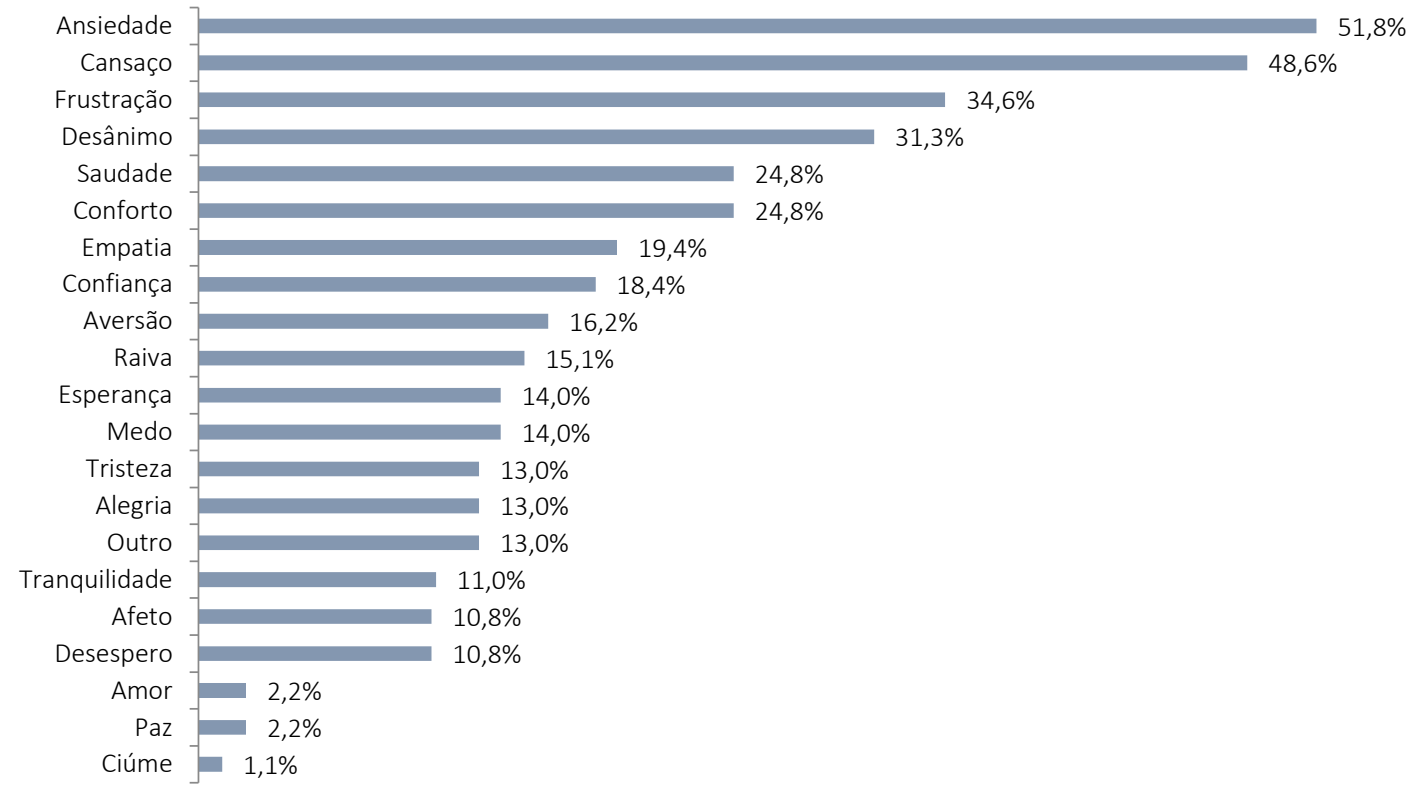

Fonte: elaborado pelos autores, com base nos dados da pesquisa (2020).

Como demonstrado no gráfico, a ansiedade $(51,8 \%)$ também foi a emoção mais citada pelos respondentes no contexto organizacional. Entretanto, diferentemente da dimensão social, as emoções que seguiram foram todas classificados de forma negativa (RICHINS, 1997), como cansaço $(48,6 \%)$, frustração $(34,6 \%)$ e desânimo (31,3\%).

Buscou-se também identificar as emoções e as percepções dos respondentes sobre a sua relação e vínculo com a organização no cenário pandêmico. $44,7 \%$ acreditam que a sua 
organização se adaptou bem à realidade da pandemia, razão pela qual se sentem seguros fisicamente e conseguem se comunicar com qualidade. Quanto à política de controle das atividades por parte da organização, $30,6 \%$ das pessoas se sentem como antes; $28,2 \%$ se sentem mais livres e menos vigiadas: $15,3 \%$ se sentem mais livres, porém mais vigiadas; $21,2 \%$ sentem-se menos livres e mais vigiadas e $4,7 \%$ se sentem menos livres e menos vigiadas. Enquanto isso, 38,8\% dos respondentes indicou preferência por manter horários fixos para executar o trabalho, contra $25,9 \%$ que preferem rotinas mais flexíveis.

Nesse sentido, 53\% sentem que sua disponibilidade online deve ser maior durante o regime de trabalho remoto e $54,1 \%$ afirmam que é comum ou muito comum serem abordados sobre assuntos profissionais em horários e dias não comerciais. Quando perguntados sobre como reagem diante de abordagens profissionais em horários não comerciais (antes das 8 horas, após as 18 horas, finais de semana e feriados), 77,8\% disseram que ao menos leem a mensagem, incluindo $40 \%$ que leem e respondem instantaneamente às mensagens recebidas.

Como observado nos dados da pesquisa, em relação às emoções, a ansiedade é a mais citada pelos respondentes nos dois contextos pesquisados - pessoal e organizacional podendo estar ligada tanto à situação do confinamento em si (VASCONCELOS et al., 2020), quanto a fatores contemplados em outras questões presentes na pesquisa, como a sensação de necessidade de estar mais disponível online e as abordagens fora de horários e dias não comerciais.

No mesmo sentido, é possível notar outras tendências de comportamento relacionadas às emoções. Além da emoção de ansiedade mencionada anteriormente, houve citações preponderantes acerca de outras emoções além das indicadas na questão. No contexto pessoal, a maioria disse sentir saudade quando utilizam meios de comunicação no seu âmbito social durante a pandemia (o que pode ser explicado pelo distanciamento social e pela nova rotina), seguida por cansaço, afeto e frustração. Emoções semelhantes também foram citadas pela maioria dos respondentes quando a questão foi repetida no contexto organizacional (ansiedade, cansaço e frustração). No contexto pessoal, dentre as cinco emoções mais citadas destaca-se uma "positiva" (afeto) e quatro "negativas" (ansiedade, saudade, cansaço, frustração), no tempo em que no contexto organizacional as emoções foram todas "negativas" (ansiedade, cansaço, frustração, desânimo, saudade), uma vez que saudade pode ser associada à solidão (RICHINS, 1997).

Foram apresentados, ainda, alguns eixos nos quais era possível escolher mais de uma ou todas as opções, sobre aspectos que a organização tem evidenciado mais, durante o distanciamento social, com relação ao respondente (Gráfico 6).

Gráfico 6 - Aspectos evidenciados como de maior importância pelas organizações

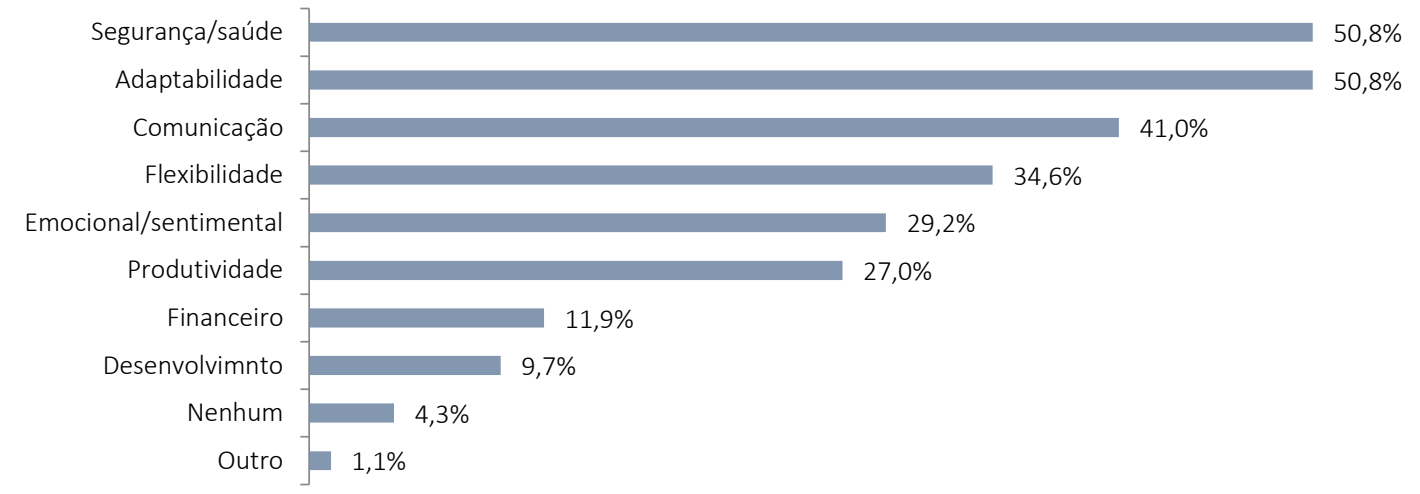

Fonte: elaborado pelos autores, com base nos dados da pesquisa (2020). 
Ainda que tenham aparecido informações negativas em relação às emoções das pessoas quando utilizam meios de comunicação organizacional, há uma percepção positiva com relação a como estes indivíduos enxergam suas organizações. Para a metade dos respondentes, a segurança, a saúde e a adaptabilidade são os aspectos que a organização tem evidenciado mais durante o distanciamento social com relação ao indivíduo. Em seguida é citada a comunicação, demonstrando que este tema é uma preocupação tanto dos gestores (ABERJE, 2020; TECCHIO, 2020) quanto dos subordinados nas organizações. Foi observado, também, que quase metade dos participantes se sente mais livre e segura, fisicamente, e consegue se comunicar com qualidade, o que serve como um feedback às preocupações que as organizações parecem ter.

Uma das questões abertas (não obrigatórias) questionava o que mudou na comunicação da organização em razão da pandemia. 25, dos 64 respondentes desta questão, mencionaram que não houve mudanças significativas na comunicação durante o período de pandemia. A objetividade foi uma qualidade mencionada com frequência entre os respondentes: "Por parte da maioria há mais objetividade e iniciativa"; "[...] ser mais sucinto ao me comunicar"; "[...] as pessoas conversam menos e se limitam aos assuntos profissionais"; "[...] a comunicação é mais direta e precisa". Entretanto, questões como a sensação de disponibilidade de resposta imediata e o aumento de atividades também foram mencionadas: "Quando estamos de home office, querem respostas imediatas, se não responder, acham que estamos fazendo outra coisa que não trabalhar"; "[...] fiquei pouco tempo remoto, quando o controle aumentou"; "[...] aumentou a quantidade de e-mails informativos e foram criados grupos de WhatsApp". Por outro lado, há também quem defenda que houve um aumento de liberdade sobre o modo como o indivíduo exerce suas atividades: "[...] ficamos mais independentes, visto que o presencial também forçava direta e indiretamente uma cobrança visual do trabalho"; "não cobram produtividade nem horários e em geral o período de expediente é respeitado nas mensagens"; "[...] gosto da flexibilidade que o trabalho em casa me proporciona".

Outra característica citada, ainda, foi com relação à frequência e à qualidade da comunicação, sendo obtidas respostas como: "[...] notícias mais frequentes de resultados"; "[...] a divulgação de eventos e informações em geral"; "[...] boletins diários"; "[...] passaram a enviar feedbacks todo mês sobre a situação da empresa, novidades e mudanças [...]". Em contrapartida, outros participantes citaram uma queda na qualidade: "Os detalhes das demandas precisam ser mais precisos"; "[...] há informações desencontradas ou que demoraram a chegar até nós"; "[...] a desorganização na hora de passar informações aos alunos".

Diferentes interpretações individuais sobre a frequência de comunicação são constatadas nas questões abertas de ambos os contextos, não havendo uma tendência observável. É possível notar que há percepções muito discrepantes entre os participantes, ainda que cheguem a se equilibrar em alguns pontos. Um deles é se acreditam que a comunicação organizacional mudou após o início do distanciamento social. Na mesma proporção acreditam que mudou para melhor, para pior ou até que não mudou.

A outra questão aberta no âmbito organizacional solicitava que fossem citados alguns aspectos alterados sobre a comunicação organizacional e que o participante espera que continuem após o fim do distanciamento social. Das respostas que podem ser classificadas como positivas, foram mencionadas a "virtualização dos processos"; antes físicos; a "flexibilidade" na jornada de trabalho e na maneira de execução das tarefas; o "dinamismo" que as comunicações virtuais trouxeram; o interesse em aprender e utilizar novas ferramentas 
com "maior difusão da informação, integração e adoção de recursos tecnológicos"; a empatia e a preocupação com o outro; as decisões mais rápidas; as reuniões remotas, que evitariam reuniões presenciais em excesso ou consideradas desnecessárias; a formalização por escrito de algumas decisões e tarefas de trabalho, antes muitas vezes feitas verbalmente; e a "objetividade e clareza" nas decisões e comandos.

Ademais, algumas das respostas relacionadas às expectativas futuras pelos respondentes mencionaram aspectos negativos, acompanhados de comentários sustentando a sua não manutenção após a pandemia. São eles: a necessidade de ser "menos intenso e mais prático, pois o volume de informações que mandam é exaustivo"; sobre o quanto "é preciso respeitar os horários"; a ineficiência na comunicação em alguns pontos; e a falta de adaptabilidade da organização a esta realidade.

É possível notar tendências em alguns dos resultados, enquanto outros não são conclusivos e tampouco demonstram tendências. Entretanto, alguns dos cenários corroboram as conclusões de outros estudos acerca da identidade dos sujeitos e dos impactos psicológicos do distanciamento social nos indivíduos, bem como as suas percepções quanto à comunicação a distância com seus amigos, seus familiares e sua organização neste período. A partir da análise dos dados levantados e à luz do referencial teórico foi possível, por fim, extrair algumas conclusões deste estudo.

\section{CONSIDERAÇÕES FINAIS}

Esta pesquisa, ainda que realizada junto a uma população reduzida e sob um caráter exploratório, buscou coletar informações que podem auxiliar no entendimento do comportamento dos indivíduos inseridos no contexto da pandemia da COVID-19, seja em seu círculo social, seja na sua relação com a organização à qual estão vinculados. O objetivo foi coletar elementos acerca da identidade e da relação do indivíduo com os meios de comunicação utilizados durante este período, ou melhor, como se sentem ao utilizá-los e como tem sido a sua relação e sua percepção individual acerca deste tema.

Analisando em conjunto as respostas dos eixos social e organizacional, é possível compreender alguns fenômenos, ainda que de modo preliminar. Um deles é a utilização predominante dos mesmos canais de comunicação em ambos os contextos: foram mencionados os aplicativos de mensagens instantâneas WhatsApp ${ }^{\circ}$, o e-mail e as videochamadas, o que aponta uma tendência à utilização de mesmos canais para assuntos distintos.

O estudo se propõe a levantar debates acerca do tema, uma vez que estatisticamente não pode ser considerado um retrato da sociedade. Contudo, é possível observar tendências, ainda que em um pequeno grupo, para algumas respostas mais comuns, reforçando os aspectos da identidade nas relações pessoais e organizacionais, especialmente ao se ter a comunicação como processo fundamental durante o distanciamento social.

À luz do referencial teórico, as diferentes interações e percepções do meio, características humanas (SILVA; HENNING, 2011; AGUIAR, 2015), foram perceptíveis nas respostas da pesquisa, apresentando significados singulares sobre suas experiências afetivas e reflexivas (MAHEIRE, 2002). As adaptações repentinas às formas de se comunicar em meio à pandemia podem ser explicadas pela condição humana de aprendizado e sua capacidade de criação de linguagens; e o uso dessas linguagens também é carregado de conotações subjetivas sobre o agir, o fazer, o pensar e o sentir (CHANLAT, 1996; HALL, 2016a). Essas diferenças se aplicam tanto na comunicação ativa quanto na passiva, uma vez que as 
percepções e sentimentos humanos são complexos e se manifestam diferentemente em cada indivíduo.

A condição de mensagens mais precisas e objetivas, citada por boa parte dos respondentes, pode esbarrar no obstáculo da linguagem administrativa, excessivamente formal e direta (CHANLAT; BÉDARD, 1996). Além disso, organizações que aparentam ter aspectos de uma estrutura burocratizada, hierarquizada, vigilante e focada em resultados, eficiência e prontidão podem dar margem a outros obstáculos relacionados com várias das respostas obtidas. Considerando a manifestação de ansiedade, cansaço, frustração e desânimo diante do uso regular dos meios de comunicação com a organização, inclusive pela frequência com que ocorrem fora dos horários e dias comerciais - e que acabam por provocar a leitura e as respostas imediatas dos respondentes aos seus interlocutores - são indicativos de que é necessário definir melhor as regras dos novos regimes de trabalho remoto, a fim de se evitar problemas, inclusive na comunicação e, por consequência, nas relações sociais.

\section{AGRADECIMENTOS}

Os autores agradecem a Fundação de Amparo à Pesquisa e Inovação do Estado de Santa Catarina (FAPESC) e à Universidade do Estado de Santa Catarina (UDESC), pelo apoio financeiro à pesquisa.

\section{REFERÊNCIAS}

AGUIAR, R. P. Noção de subjetividade na perspectiva da Psicologia Social. Psicologado, s. I. 2015. Disponível em: https://psicologado.com.br/atuacao/psicologia-social/nocao-desubjetividade-na-perspectiva-da-psicologia-social. Acesso em: 3 ago. 2020.

ASFORTH, B.; MAEL, F. Social identity theory and organization. Academy of Management Review, Nova lorque, n. 14, p. 20-39, 1989. DOI:

https://doi.org/10.5465/AMR.1989.4278999.

ASSOCIAÇÃO BRASILEIRA DE COMUNICAÇÃO EMPRESARIAL (ABERJE). Desafios da Covid-19 para a Comunicação Organizacional. São Paulo: Aberje, 2020. Disponível em: http://www.aberje.com.br/mkt_parceiros/2020/docs/aberje-pesquisaCovid19.pdf. Acesso em: 11 ago. 2020.

BRASIL. OMS declara emergência de saúde pública internacional para novo coronavírus. Notícias - Governo do Brasil. Brasília, 2020. Disponível em: https://www.gov.br/pt$\mathrm{br} /$ noticias/saude-e-vigilancia-sanitaria/2020/01/oms-declara-emergencia-de-saude-publicainternacional-para-novo-coronavirus. Acesso em: 3 ago. 2020.

BRASIL. Enfrentamento ao coronavírus: os serviços essenciais que não podem parar durante a pandemia. Notícias - Casa Civil. Brasília, 2020. Disponível em: https://www.gov.br/casacivil/pt-br/assuntos/noticias/2020/abril/enfrentamento-aocoronavirus-os-servicos-essenciais-que-nao-podem-parar-durante-a-pandemia. Acesso em: 6 out. 2020.

BROOKS, S. K.; WEBSTER, R. K.; SMITH, L. E.; WOODLAND, L.; WESSELY, S.; GREENBERG, N.; RUBIN, G. J. The Psychological impact of quarantine and how to reduce it: Rapid review of 
the evidence. The Lancet, Elsevier, v. 395, n. 10227, p. 912-920, 2020. DOI: https://doi.org/10.1016/S0140-6736(20)30460-8.

CANGUILHEM, G. Meio e normas do homem no trabalho. Pro-posições, v. 12, n. 2-3 p. 3536, jul./nov., 2001. Disponível em: https://www.fe.unicamp.br/pf-fe/publicacao/2113/3536artigos-canguilhemg.pdf. Acesso em: 12 out. 2020.

CARRIERI, A. P.; PAULA, A. P. P.; DAVEL, E. Identidade nas organizações: Múltipla? Fluida? Autônoma? Organizações \& Sociedade - v. 15, n. 45, abr./jun., 2008. Disponível em: https://www.scielo.br/scielo.php?script=sci_arttext\&pid=S1984-92302008000200010. Acesso em: 2 out. 2020.

CHANLAT, J.F. (Coord.). O indivíduo na organização: dimensões esquecidas. São Paulo: Atlas, 1996.

CHANLAT, A.; BÉDARD, R. Palavras: a ferramenta do executivo. In: CHANLAT, J.F. (Coord.). 0 indivíduo na organização: dimensões esquecidas. São Paulo: Atlas, 1996. p. 125-148.

COSTA, F. J.; ORSINI; A. C. R.; CARNEIRO, J. S. Variações de mensuração por tipos de escalas de verificação: Uma análise do construto de satisfação discente. Revista Gestão Organizacional, v. 16, n. 2. p. 132-144, 2018. DOI: http://dx.doi.org/10.21714/167918272018v16n2.p132-144.

CRESWELL, J. W. Research design: qualitative, quantitative, and mixed methods approaches. Thousand Oaks, Califórnia: Sage, 2009.

CURVELLO, J. Os estudos de comunicação organizacional e as novas abordagens sistêmicas. In: XXXII Congresso Brasileiro de Ciências da Comunicação, set. 2009, Curitiba. Anais: Curitiba: Intercom - Sociedade Brasileira de Estudos Interdisciplinares da Comunicação, 2009. Disponível em: http://www.intercom.org.br/papers/nacionais/2009/resumos/R42746-1.pdf. Acesso em: 4 ago. 2020.

DEETZ, S. Comunicação organizacional: Fundamentos e desafios. In: Marchiori, M. (Ed.), Comunicação e organização: Reflexões, processos e práticas. São Caetano: Difusora Editora, 2010.

DESLANDES, S. F.; COUTINHO, T. O uso intensivo da internet por crianças e adolescentes no contexto da Covid-19 e os riscos para violências autoinflingidas. Ciência: saúde coletiva, v. 25, supl. 1. Rio de Janeiro, 2020. DOI: https://doi.org/10.1590/141381232020256.1.11472020.

DUBAR, C. La socialisation: construction des identités sociales et professionnelles. 2. ed. Paris: Armand Colin, 1996.

FERREIRA, D. C. Estudo Técnico no 44/2019-REI-GAB. Ministério da Educação, 2019. Disponível em: https://sipac.ifes.edu.br/public/verArquivoDocumento?idArquivo= 
2146975\&key=96983be3a131421f5998ba8348d2c447\&idDocumento=238595\&downloadAr quivo=true\&publicPath=true. Acesso em: 14 out. 2020.

HATCH, M. J. Organization theory: Modern, symbolic and postmodern perspectives. 3. ed. Oxford: Oxford University Press, 2013.

HALL, S. Cultura e Representação. Tradução de Daniel Miranda e William Oliveira. Rio de Janeiro: Ed. PUC-Rio. Apicuri, $2016 a$.

HALL, S. Etnicidade: identidade e diferença. Tradução de Ana Carolina Cernicchiaro. Crítica Cultural - Critic, Palhoça, v. 11, n. 2, p. 317-327, jul./dez., 2016b. DOI:

http://dx.doi.org/10.19177/rcc.v11e22016317-327

INLOCO. Índice de isolamento social. Disponível em:

https://mapabrasileirodacovid.inloco.com.br/pt. Acesso em: 4 de ago. 2020.

INSTITUTO DE PESQUISA ECONÔMICA APLICADA (IPEA). Estudo apresenta radiografia do teletrabalho nos setores público e privado. 2020. Disponível em:

https://www.ipea.gov.br/portal/index.php?option=com_content\&view=article\&id=36278. Acesso em: 9 ago. 2020.

KRAUS, W. Making identities talk. On qualitative methods in a longitudinal study. Forum Qualitative Social Research, Berlim, s. I., v. 1, n. 2, 2000. DOI:

http://dx.doi.org/10.17169/fqs-1.2.1084.

LAVADO, T. Com maior uso da internet durante pandemia, número de reclamações aumenta; especialistas apontam problemas mais comuns. G1 Economia, 11 jun. 2020. Disponível em: https://g1.globo.com/economia/tecnologia/noticia/ 2020/06/11/com-maior-uso-da-internet-durante-pandemia-numero-de-reclamacoesaumenta-especialistas-apontam-problemas-mais-comuns.ghtml. Acesso em: 9 ago. 2020.

MACHADO, H. V. A identidade e o contexto organizacional: Perspectivas de análise. Revista de Administração Contemporânea, Edição Especial, 2003. DOI: https://doi.org/10.1590/S1415-65552003000500004.

MAHEIRIE, K. Constituição do sujeito, subjetividade e identidade. São Paulo: Interações, São Paulo, v. 7, n. 13, 2002. Disponível em:

http://pepsic.bvsalud.org/pdf/inter/v7n13/v7n13a03.pdf. Acesso em: 5 ago. 2020.

MARCONI, M. A.; LAKATOS, E. M. Fundamentos da metodologia científica. 5a edição. São Paulo: Atlas, 2003.

MARKUS, H.; NURIUS, P. Possible selves. American Psychologist, v. 41, n. 9, p. 54-969, 1986. DOI: https://doi.org/10.1037/0003-066X.41.9.954

MELLO, D. Home office foi adotado por $46 \%$ das empresas durante a pandemia. Agência Brasil, São Paulo, 28 jul. 2020. Disponível em: https://agenciabrasil.ebc.com.br 
/economia/noticia/2020-07/home-office-foi-adotado-por-46-das-empresas-durantepandemia. Acesso em: 12 ago. 2020.

MOURA, F. COVID-19: Aumento do consumo de lives e videoconferências. Revista SET, 19 jun. 2020. Disponível em: https://set.org.br/news-revista-da-set/covid-19-aumento-doconsumo-de-lives-e-videoconferencias. Acesso em: 11 out. 2020.

NEIVA, F. Comunicação das organizações: Um olhar sobre a importância da comunicação interna. Media \& Jornalismo, Lisboa, v. 18, n. 33, 2018. Disponível em: http://www.scielo.mec.pt/scielo.php?script=sci_arttext\&pid=S2183-54622018000200005. Acesso em: 12 out. 21020.

ORNELL, F.; SCHUCH, J. B.; SORDI, A. O.; KESSLER, F. H. P. "Pandemic fear" and COVID-19: mental health burden and strategies. Revista Brasileira de Psiquiatria, v. 42, n. 3, p. 232235, maio/jun., 2020 DOI: https://doi.org/10.1590/1516-4446-2020-0008.

ORGANIZAÇÃO MUNDIAL DA SAÚDE (OMS). Saúde mental e considerações psicossociais durante o surto de COVID-19. 2020. Disponível em: https://www.who.int/docs/defaultsource/coronaviruse/mental-health-considerations.pdf?sfvrsn=6d3578af_2. Acesso em: 12 ago. 2020.

PAVLOV, I. P. Reflexos condicionados e inibições. Rio de Janeiro: Zahar, 1963

PUTMAN, L.L.; PHILLIPS, N.; CHAPMAN, P. Metáforas da comunicação e da organização. In: CLEGG, S.; HARDY, C.; NORD, W.R. Handbook de estudos organizacionais. São Paulo: Atlas, 2004. 3 v., p. 77-125.

RICHINS, M. L. Measuring emotions in the consumption experience. Journal of Consumer Research, Chicago, fev. 1997. DOI: https://doi.org/10.1086/209499.

SCHEID, D.; MACHADO, J.; PÉRSIGO, P. O cenário (mutável) da comunicação organizacional e das relações públicas. In: Tendências em comunicação organizacional: Temas emergentes no contexto das organizações. Estrato - Grupo de pesquisa em Estratégias Midiáticas Organizacionais. FACOS - UFSM. Frederico Westphalen, 2019. Disponível em: https://www.ufsm.br/app/uploads/sites/330/2019/12/ebook-Tend\%C3\%AAncias.pdf. Acesso em: 10 out. 2020.

SCHMIDT, B.; CREPALDI, M. A.; BOLZE, S. D. A.; NEIVA-SILVA, L.; DEMENECH, L. M. Saúde mental e intervenções psicológicas diante da pandemia do novo coronavírus (COVID-19). Estudos de Psicologia, Campinas, v. 37, e200063, p. 1-13, 2020. DOI: http://dx.doi.org/10.1590/1982-0275202037e200063.

SILVA, R. B.; HENNING, L. M. P. A construção da subjetividade: notas sobre o sujeito. Human and Social Sciences, Maringá, v. 33, n. 1, p. 67-47, 2011. DOI:

https://doi.org/10.4025/actascihumansoc.v33i1.9439. 
TAJFEL, H. Grupos humanos e categorias sociais. Tradução de Lígia Amâncio. Lisboa: Livros Horizonte, 1982.

TECCHIO, M. Home office: chefes e funcionários relatam problemas, mas a avaliação é positiva. CNN Business, São Paulo, 24 maio 2020. Disponível em:

https://www.cnnbrasil.com.br/business/2020/05/24/home-office-chefes-e-funcionariosrelatam-problemas-mas-a-avaliacao-e-positiva. Acesso em: 11 ago. 2020.

VASCONCELOS, S. S. C., FEITOSA, I O., MEDRADO, P. L. R., \& BRITO, A. P. B. O novo coronavírus e os impactos psicológicos da quarentena. Desafios - Revista Interdisciplinar da Universidade Federal do Tocantins, v. 7 (Especial-3), p. 75-80, 2020. DOI: https://doi.org/10.20873/uftsuple2020-8816.

VIGNOLES, V. L.; SCHWARTZ, S. J.; LUYCKX, K. Introduction: Toward an integrative view of identity. In: SCHWARTZ, S. J. et al. (eds.), Handbook of Identity Theory and Research. Springer Science \& Business Media. Universidade de Sussex, Reino Unido, 2011. Disponível em: https://www.researchgate.net/publication/225212182_Introduction_ Toward_an_Integrative_View_of_Identity. Acesso em: 12 out. 2020.

WANG, C., PAN, R., WAN, X., TAN, Y., XU, L., HO, C. S., \& HO, R. C. Immediate psychological responses and associated factors during the initial stage of the 2019 coronavirus disease (COVID-19) epidemic among the general population in china. International Journal of Environmental Research and Public Health, v. 17 n. 5, p. 17-29, 2020. DOI: http://dx.doi.org/10.3390/ijerph17051729.

WHETTEN, D. A.; GODFREY, P. C. Identity in organizations, building theory through conversations. Londres: Sage, 1998. 